\title{
FILLING THE VOID
}

\section{A REFLECTION}

\section{Lindy Rudd}

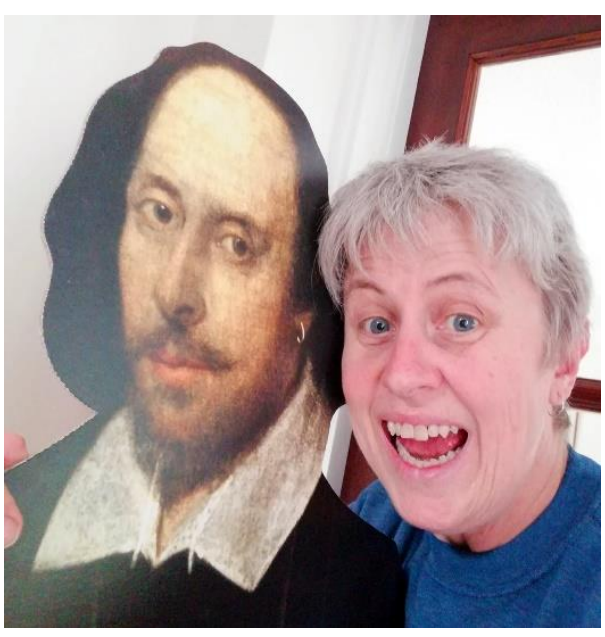

PhD Researcher/Associate Tutor, Department of English and Comparative Literary Studies, University of Warwick Correspondence: lindy.rudd@warwick.ac.uk

Lindy Rudd is a third year PhD student in English and Comparative Literary Studies. Her research highlights hidden forms of exclusion embedded in the GCSE English language syllabus and the mandatory resit policy of contemporary Further Education, by comparing similar marginalisation explicit in early modern elementary education. Lindy has been a seminar tutor for a year and also tutored as part of the National Tutoring Programme during the pandemic. Previously, she taught English at a city FE college. At home, her study overlooks a castle mound where Henry Bolingbroke, the antagonist from her favourite Shakespearean history play, lived as a child.

\begin{abstract}
This reflective piece records my experience of switching to online seminars during the pandemic with small groups of first year English literature undergraduates. I reflect on issues I experienced promoting student interaction in small group seminars and how professional development opportunities available through the Warwick Academic Development Centre helped with my use of technology and improving the level of engagement. I hope that it contains some ideas which may be useful starting points for PGRs looking to develop flipped or blended learning environments in the future. Perhaps it will also shed light on the way the current cohort of students reacted to online learning which may help in supporting them when returning to more traditional, or, more likely, hybrid pedagogies.
\end{abstract}

Keywords: digital learning, communication, interaction, engagement, social presence.

\section{Filling the Void}

I'm a qualified teacher in further and college higher education, so I have teaching experience, but Autumn 2020 was the first time I had taught in an "actual" university. I was allocated two small groups of ten and twelve predominantly first years, but with some intermediate and Erasmus students. I expected to learn new skills, as the student demographic wasn't familiar to me, but I wasn't prepared for what was about to 
happen! When my department announced that lectures and seminars would be moved online, I assumed it would be a simple matter of using existing teaching practices, but via video link. How wrong I was. Poor, naïve fool!

The first problem we encountered was getting access to reliable internet connections. I live in a rural area, and my bandwidth couldn't cope with running Microsoft Teams. Students on campus found that they had numerous problems with hardware, and the university's IT infrastructure initially seemed unprepared for the massive increase in online traffic. If students turned their cameras on their screens would freeze, the audio would periodically drop out so we could only hear one in every five words, multiple students would unmute their microphones at the same time and the only sound we could hear would be feedback, and I lost count of the number of times the 'unstable connection' message appeared, signalling a complete breakdown in communication. 'Teams' became a byword for calamity. My first attempt using breakout groups (in 'Channels' before the 'Rooms' function was enabled) took an awful lot of setting up but resulted in losing all the students into the ether mid-seminar. Hardly my finest hour. I felt that technology was preventing me from developing any meaningful engagement with the students.

IT issues were soon ironed out. Although it felt like forever at the time, this happened relatively quickly, and Teams constantly improved functionality. Come the start of the spring term, very few problems remained - but there was a new bogeyman: teaching into the void. By this time, cameras were never on, supposedly to save bandwidth, so l'd often find myself faced with a screen full of blank squares. I'd pose a question, then sit back and admire the tumbleweed rolling past, not knowing if the students were still there or if they'd got bored and nipped off for a coffee.

I found there was a real reluctance to communicate via spoken word using an online platform. Language is naturally a very sociable medium of expression and of course we had all missed the social, face-to-face element. With cameras off and microphones muted, the very nature of online communication had altered teaching and learning completely. Speech became monologic; students didn't ask questions. There was no hedging, overlapping conversation, interruptions, gestures, facial expressions, or any of the cues and support mechanisms associated with spoken discourse. It became codified in another way - raising a Simpsons-like yellow paw to signal intent and then feeling the pressure to make an extended contribution -and none of us were comfortable with how it worked. From the students' point of view, I worried that they were losing the opportunity to develop critical thinking skills and explore complex perspectives on subject material. Because they weren't responding to each other, I felt active learning strategies, typical of seminars, were being compromised. From my own point of view, I couldn't interpret subtle signals, such as when a student wanted to contribute but lacked the confidence to interject, or whether they dreaded being singled out. I rely heavily on a physical presence in a classroom for a constant flow of information, but I had no idea what was going on behind those blank screens. One student told me during a 'virtual' office hour, 'Some of the things you say are hilarious, but I can't turn my microphone on just to laugh. That would be so weird.' Thank goodness! I had even started to think my jokes were rubbish. Whereas in a face-to-face situation, the group supports each other's contributions with verbal and non-verbal cues, these communication tools were simply not there in the online environment. It resulted in a different form of speech that lacked the dynamism of spoken communication and was more akin to presentation. As a result, I was finding it very difficult to facilitate a meaningful exchange of ideas within the seminar sessions.

My initial response was to perceive the lack of interaction as a temporary problem that I needed to wait out rather than fix, caused by the inferior nature of teaching and learning in cyber-space. However, before the pandemic, I 
had enrolled on the Warwick Academic Development Centre's APP PGR course. This too was moved online and became the biggest boon in developing new pedagogies to support student engagement. To start with, it gave me the chance to be an online student and understand first-hand how it felt to learn in a digital environment. Not only did I benefit from top-class tuition, introducing me to pedagogies I could use and experiment with, but I found having the support of my peers was invaluable. It helped me to realise that instead of waiting for everything to go back to normal, our challenge was responding to the unique nature of the pandemic to try and give the students the best experience of learning that we possibly could. Why should they settle for 'temporary' or 'inferior' now it was clear this wasn't a short-term problem? To realise that I wasn't the only one 'teaching into the void' made such a difference as my first thought had been 'is it something I'm doing wrong?' I found a network of people with a similar experience who I could talk to and who were as committed as I was to solve the issue of engagement we were facing.

On one fortuitous occasion, I was signposted to the Moodle course 'Teaching for Learning Online for PGR Teachers' and the part I found particularly interesting was 'The Role of the Tutor'. It all started to make sense when I read this, that in effect, I'd neglected my 'social presence' because I was at much at sea as the undergraduates without face-to-face contact. Anthony McMullen describes how vital a teacher's physical presence is to facilitating student interaction and in a digital space there needs to be a similar 'humanizing' element (McMullen et al. 2020: 42). In a physical space, I'd talk to students and offer encouragement, so why not virtually? I quickly pinged off an email reminding them of my availability, where to find information, and saying:

You've worked so hard to get this far under difficult circumstances. Just think back to the start of the year, how overwhelming everything was, and now you can discuss the epic genre so knowledgably AND we can all make
Teams work! I'm really looking forward to reading what you have to say about the texts. You've got this.

This doesn't seem like much, but l'd genuinely overlooked how much the simple things count towards building a relationship with students, even in an online environment. I had a couple of responses almost immediately. One student wrote, 'Thank you so much for giving me a bit of optimism amidst all this.' As Jean Kidd and Warren Murray from the University of East London so perfectly summarise: 'It is by applying old values to new spatialities that educators maintain meaningful and just practices, innovating into new and professionally rich disembodied spaces' (Kidd \& Murray 2020: 554). I was reminded that old values remain important, even if old methods did not.

My approach then focussed on managing those 'disembodied spaces'. According to a 2020 study at Xavier University, Ohio, lack of interaction is often the key component preventing engagement in an online teaching environment (Wu \& Jin 2020: 153). If students weren't going to talk to me, I had to find another way to interact and so I set about extending my personal 'toolkit' of digital learning tools. I used Vevox for quizzes to introduce an element of gamification (also very useful as a diagnostic assessment tool), Padlet for asynchronous tasks and online discussion, and Nearpod for starter activities and discussion via the 'collaborate board'. Padlet and Nearpod were useful to pose a range of question types, from those requiring narrowly defined responses to more divergent questions. Interestingly, when I invited students to respond via these platforms, every single one of them participated. This was a very different experience to the silence I encountered when relying on them to volunteer verbally. I particularly liked Nearpod as I could set it as a student-paced lesson after the seminar so any who had missed the session could go through the activities independently. Even if they hadn't been involved in the seminar discussion, it was a simple matter to add extra content to make it a standalone resource, and the others could 
revisit the material to consolidate their learning. The level of student interaction via these platforms confirmed that I needed to stop trying to solve a problem with spoken communication online and instead reframe the issue. Although in my mind's eye the exemplar of interactive learning included a belief in the primacy of speech for the seminar environment, I had to admit that maybe it was no longer relevant to an online environment.

In term 2, I tasked small groups with leading the seminars. I hoped that handing them the reins would create a bit of social cohesion as well as honing subject-related skills. However, it wasn't quite the success I had hoped for in terms of encouraging more interaction. I thought the students might support each other by increasing the level of verbal contribution during the sessions, as beforehand they had cited 'teaching into the void" as the "worst" thing that could happen. However, they didn't seem to have developed the level of cohesion where they felt responsibility towards each other, and each group met a wall of silence from their peers (and I admit I felt the tiniest touch of schadenfreude). In addition, I viewed my students as 'digital natives' and myself, being older, as a 'digital immigrant' and so it was something of a surprise to learn that they were as unfamiliar with learning technologies as I had been at the start of the pandemic and didn't pick them up intuitively. I just assumed they would already be skilled with using similar interfaces. I had to guide them through things like enabling video sound, sharing apps, and setting up breakout spaces. I think one big difference was that, inspired by my experience of APP PGR, I set out to learn how to use these new technologies as a focus of my professional development during, and because of, the pandemic, whereas the students didn't expect 'using educational apps' to suddenly appear on their reading list. They did, though, get to work with some new learning technologies which, I hope, gave them opportunities to develop wider skills outside of taught content. I feel this could be more important than ever in the future with more people working remotely, and more meetings conducted using video technology.

So, as we return to more traditional pedagogies, what am I going to take away from the experience of the last academic year? Certainly the time I invested in mastering new learning technologies was worthwhile and I will be making more use of digital platforms in the future for asynchronous tasks. One student's end-of-year reflection described the seminars as 'fun, never boring and way more styles of teaching than other modules' which seems like a thumbs-up, albeit a yellow, virtual thumb. Students seemed comfortable with digital learning platforms as a low-risk medium for contributing their ideas, and those contributions can act as a scaffold for higher risk, real-time critical thinking during the seminar. I will also remember that being a digital native does not automatically mean breadth of use and so I will offer support to my students in the future in the use of any new technologies that I use. I'm still thinking about how to improve teamwork and cohesion in the online environment because I don't think I came anywhere near to solving that issue. It might just get better by itself when face-to-face teaching is reinstated but that doesn't mean it will stop being important: blended learning is here to stay. Finally, I will continue to surround myself with people who want to keep learning about teaching, however much they already know, however much experience they have. I could never have made it through this past year without them.

\section{References}

Kidd, J. \& Murray, W. (2020) 'The Covid-19 pandemic and its effects on teacher education in England: how teacher educators moved practicum learning online', European Journal of Teacher Education, (43.4): 542-558. https://doi.org/10.1080/02619768.2020.1820480 (Accessed 18th March 2021)

McMullen, A., Bursuc, V., Doval, C., Grant, S., Grossberg, J., Jones, I., \& Willey, S. (2020) 
'Strategies for Effective Online Teaching in Higher Education', Business Education Innovation Journal, (12:2): 40-48.

http://dx.doi.org/10.2139/ssrn.3745959

Wu, L. \& Jin, A. (2020) 'Perspectives on

Student Interaction of Online Teaching',
Business Education Innovation Journal, (12:1): 149-159.

http://www.beijournal.com/images/V12 N1 fin al 9 11.pdf

To cite this article: Lindy Rudd. 2021. Filling the Void - A Reflection. Journal of PGR Pedagogic Practice. 1, 20-24. Available at: [URL] 